\title{
Journal of Obesity \& Metabolic Syndrome: A New International Journal Targeting the Pathophysiology and Treatment of Obesity and Metabolic Syndrome
}

\author{
Soo Lim* \\ Editor in Chief, Journal of Obesity \& Metabolic Syndrome \\ Division of Endocrinology and Metabolism, Department Internal Medicine, Seoul National University College \\ of Medicine and Seoul National University Bundang Hospital, Seongnam, Korea
}

\author{
${ }^{*}$ Corresponding author \\ Soo Lim \\ http://orcid.org/0000-0002-4137-1671 \\ Department of Internal Medicine, Seoul \\ National University College of Medicine \\ and Seoul National University Bundang \\ Hospital, 82 Gumi-ro 173beon-gil, \\ Bundang-gu, Seongnam 13620, Korea \\ Tel: +82-31-787-7035 \\ Fax: +82-31-787-4051 \\ E-mail:limsoo@snu.ac.kr
}

Obesity is growing in an epidemic fashion and obesity-related disorders contribute substantially to health-care costs and mortality. ${ }^{1}$ Obesity and overweight are major risk factors for conditions ranging from nonalcoholic fatty liver disease, insulin resistance, diabetes mellitus, ischemic heart diseases, stroke, and some types of cancers. ${ }^{2,3}$ It is obvious that obesity - particularly abdominal obesity-is associated with an increased risk of atherosclerosis, which is mainly because of its close association with an atherogenic dyslipidemic state characterized by high triglyceride levels, increased circulating apolipoprotein-B, and an increased proportion of small dense low-density lipoprotein cholesterol and of low high-density lipoprotein cholesterol levels. ${ }^{4,5}$ Obesity is also associated with other adverse health conditions, such as arthritis and arthralgia, sleep apnea syndrome, mental disorders, and infections. Thus, being overweight or obese has become a major clinical and public health problem. The problems induced by obesity are found not only in Western countries but also in Asia.

Metabolic syndrome is a cluster of factors linked with metabolic impairment, which increases cardiometabolic morbidity and mortality as well as all-cause mortality. ${ }^{6}$ Metabolic syndrome is based on insulin resistance and is also associated with the development of nonalcoholic fatty liver disease and type 2 diabetes. Indeed, metabolic syndrome predisposes individuals to developing type 2 diabetes and cardiovascular diseases. In the USA, $23.7 \%$ of the population ( $24.0 \%$ of men and $23.4 \%$ of women) was classified as having metabolic syndrome by the National Cholesterol Education Program-Adult Treatment Panel III definition when the third National Health and Nutrition Examination Survey (NHANES) data were used. ${ }^{7,8}$ At present, about 100 million American adults are reported to be affected by metabolic syndrome. Furthermore, Asian-Americans were found to have a higher prevalence of metabolic syndrome than did CaucasianAmericans, after adjusting for age, body size, body composition, and smoking, alcohol, and exercise habits. ${ }^{9}$ According to the data from the Korea National Health and Nutrition Examination Surveys (KNHANES) with a total of 6,907, 4,536, 5,373, and 2,890 Koreans aged $\geq 20$ years in 1998, 2001, 2005, and 2007 surveys, respectively, the prevalence of metabolic syndrome have significantly increased from $24.9 \%$ in 1998, 29.2\% in 2001 and $30.4 \%$ in 2005 to $31.3 \%$ in $2007 .{ }^{10}$ Among teenagers, the age-adjusted 
prevalence rates of metabolic syndrome reported in KNHANES has increased from $4.0 \%$ to $5.9 \%, 6.6 \%$, and $7.8 \%$ in the 1998 , 2001, 2005, and 2007 surveys, respectively. ${ }^{11}$ These findings imply that we are going to face a huge number of subjects with metabolic syndrome in the near future. ${ }^{12}$

The official journal of the Korean Society for the Study of Obesity has played an important role as a representative journal in the fields of obesity and its related disorders since 1992. After that first issue was released, diverse studies on obesity have been published under the title Journal of Korean Society for the Study of Obesity until 2004. From 2005 to 2016, its title was the Korean Journal of Obesity (pISSN 2383-899X, eISSN 2234-7631). Since 2017 (volume 26), the title is now the Journal of Obesity \& Metabolic Syndrome. The journal is published quarterly on March 30, June 30, September 30 and December 30 annually. The official title of the journal is now the Journal of Obesity \& Metabolic Syndrome and the abbreviated title is "J Obes Metab Syndr." Index words from the medical subject headings (MeSH) (https:// meshb.nlm.nih.gov/search) list of Index Medicus are included in each article to facilitate article searching. All the articles of this journal are included in the indexes of Ebsco, KCI, KoreaMed, KoMCI, Science Central, and DOI (10.7570)/Crossref. The journal is also published on the official website of the Journal of Obesity \& Metabolic Syndrome (http://www.jomes.org) and is widely distributed not only to members of the Korean Society for the Study of Obesity but also to domestic and international subscribers, medical schools, libraries, and academic institutions.

The Journal of Obesity \& Metabolic Syndrome is an official, peerreviewed research journal published by the Korean Society for the Study of Obesity. Its aim is to improve the understanding, prevention, and treatment of obesity, to improve the lives of those affected, and thereby to reduce the incidence of obesity-related metabolic disorders. We hope to contribute to the cure and education of obesity through the sharing of scientific information on the latest developments in obesity among members of the Korean Society for the Study of Obesity and other international societies dealing with obesity. We publish articles covering all aspects of obesity, particularly its epidemiology, including prevalence and characteristics, etiology, diagnosis, pathogenesis, and management, such as lifestyle modifications and pharmacological therapy. ${ }^{13}$
Our articles include research papers on the basic and clinical medicine of obesity and obesity-related disorders, as well as the specific applications of appropriate studies in biochemistry, physiology, genetics, and metabolism. Nutritional, exercise, psychological and epidemiological aspects are also included in our topics. As the complications of obesity are more related to visceral adiposity/ectopic fat than to an excess of body fat, proper preventive and/or therapeutic interventions should be developed. So, topics about prevention of obesity are always welcome. Furthermore, fat accumulation around ectopic sites has attracted particular attention because it can be associated with regional health problems. Therefore, we welcome manuscripts that include novel approaches based on pathophysiological considerations. The types of articles published include original articles, editorials, reviews, short communications, case reports, and letters to the editor.

We think that solving the problems of obesity must be accompanied by considering various aspects of psychosocial and economic problems. Therefore, the most important principle of this journal is that dietitians, sports curers, psychiatrists, psychologists, nutritional and sport scientists as well as endocrinologists and internists can participate in it as readers and authors.

This new beginning with the Journal of Obesity \& Metabolic Syndrome will help maintain academic standards and take the lead in the development of the fields of obesity and metabolic syndrome. Our academic editors hope that this new journal will be accessed and referred to easily by everybody at any time.

I believe that basic role of scientific journals is to share the information obtained from academic research and to contribute to future advances. I hope that the Journal of Obesity \& Metabolic Syndrome will go beyond the simple communication of knowledge among obesity experts and will become a solid platform for aiming for scientific progress in this field.

I will appreciate any constructive critiques, comments, or suggestions you may have. Most of all, I will always welcome the submission of your valuable manuscript to the Journal of Obesity \& Metabolic Syndrome.

\section{CONFLICTS OF INTEREST}

The author declares no conflict of interest. 


\section{ACKNOWLEDGMENTS}

I thank Ms Ae Li Lee for her invaluable assistance in editing manuscripts.

\section{REFERENCES}

1. Olshansky SJ, Passaro DJ, Hershow RC, Layden J, Carnes BA, Brody J, et al. A potential decline in life expectancy in the United States in the 21st century. N Engl J Med 2005;352:1138-45.

2. Calle EE, Rodriguez C, Walker-Thurmond K, Thun MJ. Overweight, obesity, and mortality from cancer in a prospectively studied cohort of U.S. adults. N Engl J Med 2003;348:1625-38.

3. Brawer R, Brisbon N, Plumb J. Obesity and cancer. Prim Care 2009;36:509-31.

4. Després JP, Lemieux I, Bergeron J, Pibarot P, Mathieu P, Larose E, et al. Abdominal obesity and the metabolic syndrome: contribution to global cardiometabolic risk. Arterioscler Thromb Vasc Biol 2008;28:1039-49.

5. Després JP, Lemieux I. Abdominal obesity and metabolic syndrome. Nature 2006;444:881-7.

6. Grundy SM, Brewer HB Jr, Cleeman JI, Smith SC Jr, Lenfant C; American Heart Association, et al. Definition of metabolic syndrome: report of the National Heart, Lung, and Blood Institute/American Heart Association conference on scientific issues related to definition. Circulation 2004;109:433-8.
7. Ford ES, Giles WH, Dietz WH. Prevalence of the metabolic syndrome among US adults: findings from the third National Health and Nutrition Examination Survey. JAMA 2002;287: 356-9.

8. Mozumdar A, Liguori G. Persistent increase of prevalence of metabolic syndrome among U.S. adults: NHANES III to NHANES 1999-2006. Diabetes Care 2011;34:216-9.

9. Rajpathak SN, Gupta LS, Waddell EN, Upadhyay UD, Wildman RP, Kaplan R, et al. Elevated risk of type 2 diabetes and metabolic syndrome among Asians and south Asians: results from the 2004 New York City HANES. Ethn Dis 2010;20: 225-30.

10. Lim S, Shin H, Song JH, Kwak SH, Kang SM, Won Yoon J, et al. Increasing prevalence of metabolic syndrome in Korea: the Korean National Health and Nutrition Examination Survey for 1998-2007. Diabetes Care 2011;34:1323-8.

11.Lim S, Jang HC, Park KS, Cho SI, Lee MG, Joung H, et al. Changes in metabolic syndrome in American and Korean youth, 1997-2008. Pediatrics 2013;131:e214-22.

12. Hong AR, Lim S. Clinical characteristics of metabolic syndrome in Korea, and its comparison with other Asian countries. J Diabetes Investig 2015;6:508-15.

13. Lim S, Eckel RH. Pharmacological treatment and therapeutic perspectives of metabolic syndrome. Rev Endocr Metab Disord 2014;15:329-41. 